\title{
Influence of exogenous pigmentation on the optical properties of orthodontic elastic ligatures
}

\author{
Alline Birra Nolasco FERNANDES ${ }^{1}$, Alexandre Antonio RIBEIRO², Marcus Vinicius Almeida de ARAUJO², Antônio \\ Carlos de Oliveira RUELLAS ${ }^{4}$

\begin{abstract}
1- Student of Masters in Orthodontics, Department of Odontopediatrics and Orthodontics, Dental School, Federal University of Rio de Janeiro (FO-UFRJ), Rio de Janeiro, RJ, Brazil.

2- Master in Orthodontics, Department of Orthodontics, Dental School, Federal University of Rio de Janeiro (FO-UFRJ), Rio de Janeiro, RJ, Brazil. 3- Master in Orthodontics, Department of Orthodontics, Dental School, Federal University of Rio de Janeiro (FO-UFRJ), Rio de Janeiro, RJ, Brazil; Professor of Dentistry, Potiguar University; specialization in Orthodontics, Brazilian Association of Dentistry, Natal, RN, Brazil.

4- MS, PhD, Faculty of Dentistry, Department of Orthodontics, Federal University of Rio de Janeiro (FO-UFRJ); Associate Professor of Orthodontics, FOUFRJ, Rio de Janeiro, RJ, Brazil.
\end{abstract}

Corresponding address: Alline Birra Nolasco Fernandes - Faculdade de Odontologia, Departamento de Ortodontia - Av. Professor Rodolpho Paulo Rocco, n³25 - 21941617 - Rio de Janeiro - RJ - Brasil - Phone: (55) 2125902727 - Fax: (55) 2125909771 - e-mail: allinebirra@hotmail.com

Received: November 5, 2011 - Modification: July 14, 2011 - Accepted: August 15, 2011

ABSTRACT

bjectives: The aim of this study was to assess the optical properties of orthodontic elastic ligatures under the influence of exogenous pigments contained in the daily diet. Material and methods: For the analysis, colorless (clear) elastic segments (ORTHO Organizers, lot 660625A10) were used as received from the manufacturer, and were divided into 8 groups of 3 segments each. Each group was immersed in $200 \mathrm{~mL}$ of a solution containing a determined substance, as follows: distilled water (control group), Coca-Cola ${ }^{\circledR}$, Pomarola brand tomato sauce $\left(\mathrm{Cica}^{\circledR}\right)$, açai, Jasmine ${ }^{\circledR}$ brand green tea, Royal Blend ${ }^{\circledR}$ black tea brand, Pilão ${ }^{\circledR}$ brand coffee and Palmares ${ }^{\circledR}$ wine brand. All test specimens were immersed in the solutions and kept in an appropriate receptacle for 7 days at $37^{\circ} \mathrm{C}^{14}$. After the staining session, the test specimens were washed with distilled water in an ultrasonic vat for 5 min and dried with paper tissues ${ }^{6}$. The portable digital spectrophotometer Vita Easyshade Compact was used to assess if there was color variation of the test specimens. This variation was quantified and qualified at the initial time (T0) and after staining (T1). Results: These results were analyzed statistically using the software SPSS version 18.0. The Shapiro-Wilk test of normality was applied followed by the one-way analysis of variance and the Tukey's post hoc test. The level of significance adopted was 5\%. Conclusions: From the substances evaluated in this study, those with higher staining potential on esthetic elastic ligatures were black tea, coffee and wine, respectively. Knowing this information, the dentist may advise their patients to avoid certain foods because of elastic staining may occur thus decreasing the aesthetics of the material.

Key words: Optical properties. Orthodontic appliances. Elastic ligatures.

\section{INTRODUCTION}

Esthetics has become a demand even during orthodontic treatment, particularly in adult patients, who do not like accessories that call people's attention. In a recent study with 27 -year-old individuals in Sweden, $67 \%$ of the interviewees would wear metal brackets if needed, which means that one third of young adults would refuse to wear non-esthetic brackets ${ }^{23}$. For this reason, the number of esthetic products has significantly increased on the orthodontic market, such as brackets, Teflon- covered wires, lingual brackets, colorless elastics, among others.

Patients who seek invisibility of orthodontic appliances usually prefer colorless elastic ligatures (crystal) $^{2}$ that complement the good appearance of esthetic brackets ${ }^{12}$. However, after a few weeks, when the patients return for maintenance of the orthodontic appliance, yellowing of the elastics is visibly clear $^{12}$. It is reported in the literature that color degradation occurs due to endogenous factors, such as ultraviolet irradiation and thermal energy, and exogenous factors, such as pigmented foods 
and beverages and mouthwashes ${ }^{13,19}$

Therefore, preventing stains on the elastics has become a significant challenge since the oral environment is exposed to several substances in the daily diet that stain or alter the surface causing esthetic degradation ${ }^{2}$. Studies also reveal that prolonged exposure to Coca-Cola ${ }^{\circledR}$ causes color alteration in restorative resins ${ }^{1,7}$. Other products that may cause staining are spices, which are important products in processed foods (prepared foods, snacks, sauces, condiments, salad dressings) and in typical Mexican, Italian and Asiatic foods².

Innumerable studies in the areas of Dentistry and Prosthesis have endeavored to establish the influence of foods and beverages on the color stability of resin composite and porcelain restorations. However, in the orthodontic literature, little is found on the subject probably due to limitations in measuring the colors of the objects until a few years ago. Nowadays, studies frequently use colorimeters, digital cameras or spectrophotometers to assess color alterations. Color degradation of elastic ligatures (clear) of all the manufacturers tested was higher than the threshold of human visual perception, and the value of $3.7^{2,5,11,12}$ has been shown by various authors ${ }^{11}$.

In an attempt to further characterize the exogenous color alteration of elastic ligatures under the influence of foods and beverages, this study assessed the possible color change of colorless elastic ligatures according to the different types of food and beverage.

\section{MATERIAL AND METHODS}

Twenty-four colorless (clear) elastic segments from the manufacturer ORTHO Organizers, Carlsbad, CA, USA, lot 660625A10, were used to assess color stability.

For the analysis, elastic segments were used as presented by the manufacturer (Figure 1). They were divided into 8 groups of 3 segments each. Each group was immersed in one of the following substances: distilled water (control group), CocaCola ${ }^{\circledR}$, Pomarola brand tomato sauce ( $\mathrm{Cica}^{\circledR}$ ), açai, Jasmine $^{\circledR}$ brand green tea, Royal Blend ${ }^{\circledR}$ black tea brand, Pilão ${ }^{\circledR}$ brand coffee and Palmares ${ }^{\circledR}$ wine brand.

\section{Staining}

After dividing the elastic segments into groups, they were immersed in $200 \mathrm{~mL}$ of each solution tested. The green and black tea and coffee solutions, which needed previous preparation, were made in accordance with the manufacturer's instructions.

The green tea solution was prepared using 2 teabags immersed in $200 \mathrm{~mL}$ of boiling distilled water for $10 \mathrm{~min}$. The black tea solution was prepared using 2 teabags immersed in $200 \mathrm{~mL}$ of boiling distilled water for $10 \mathrm{~min}^{21,22}$. The coffee solution was prepared using $6 \mathrm{~g}$ of coffee in 200 $\mathrm{mL}$ of boiling distilled water poured into a paper filter. All the test specimens were immersed in the solutions and kept in an appropriate receptacle for 7 days at $37^{\circ} \mathrm{C}^{3}$, equivalent to the recommended time of 21 days to exchange elastic during the consultation service.

After the staining session, the test specimens were washed with distilled water in an ultrasonic vat for 5 min and dried with paper tissues ${ }^{20}$.

\section{Sample reading}

The portable digital spectrophotometer Vita Easyshade Compact was used to assess if there was variation of shine and color of the test specimens. This variation was quantified and qualified at the initial time (T0) and after staining (T1).

The measurement of translucent materials is influenced by background properties ${ }^{16}$. There are different possible backgrounds to make this measurement. The fund could be black, white or mirrored. Among these a mirrored surface dimensions of $15.5 \times 7.5 \mathrm{~mm}^{2}$ was chosen to avoid any interference. For the measurements, the

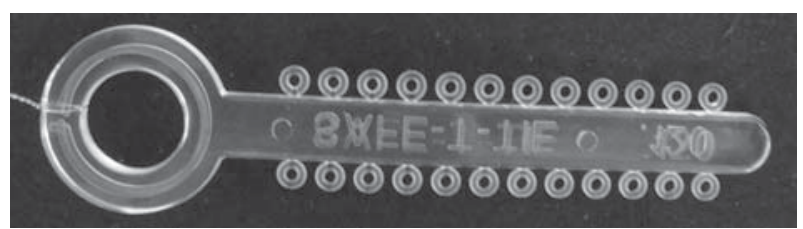

Figure 1- Test specimen before staining

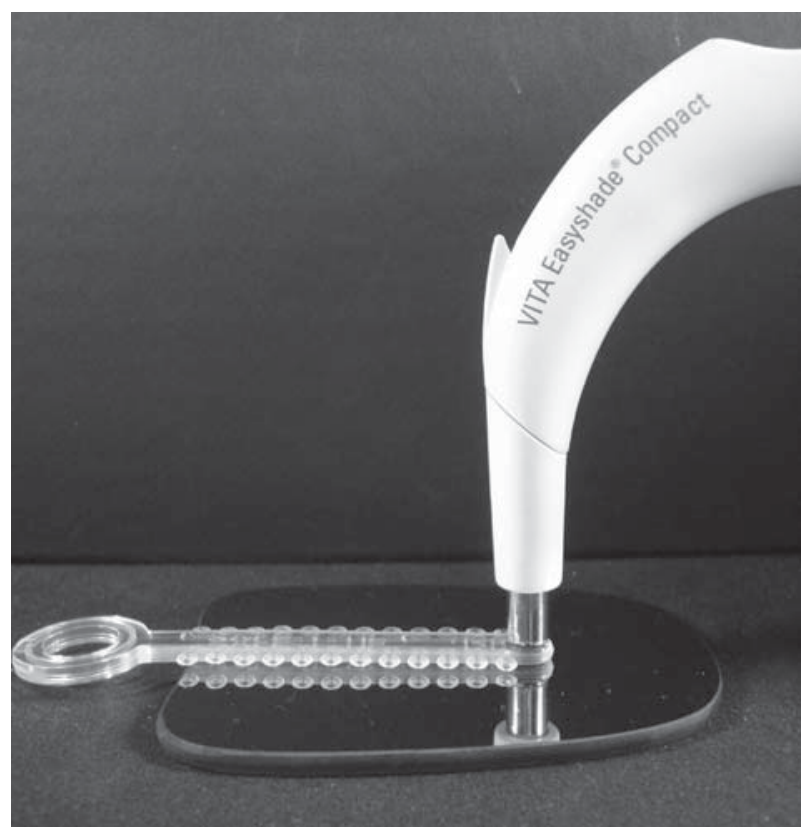

Figure 2- Position of the digital spectrophotometer on the standardized area and the test specimen on the mirrored surface 
spectrophotometer was placed perpendicularly on a standardized area of the test specimen (Figure 2). Reading was performed in the same ambient, all on the same day without any light difference.

For each test specimen, 5 measurements were made and the values of $a, b, L$ and the specific color on the classical VITAPAN ${ }^{\circledR}$ scale were obtained. The $\Delta \mathrm{E}$ values were obtained using the formula $\Delta \mathrm{E}^{*}=\left[(\Delta \mathrm{L})^{2}+(\Delta \mathrm{a})^{2}+(\Delta \mathrm{b})^{2}\right]^{1 / 2}$ where $\Delta \mathrm{L}, \Delta \mathrm{a}, \Delta \mathrm{b}$ are the differences in the values of $L, a$ and $b$ before staining (T0) and after staining (T1). These results were statistically analyzed using the software SPSS

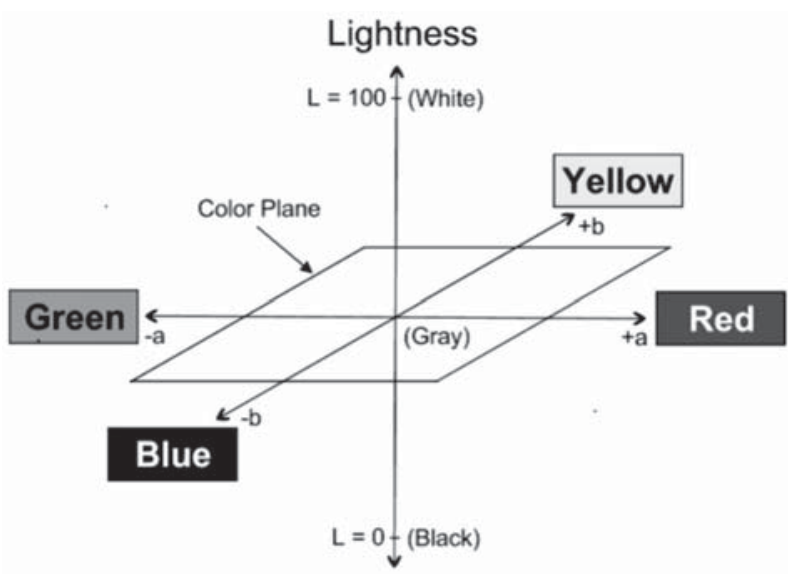

Figure 3- $\mathrm{CIEL}{ }^{*} \mathrm{a}^{*} \mathrm{~b}^{*}$ color scale version 18.0 (Statistical Package for Social Sciences, SPSS Inc., Chicago, IL, USA). The Shapiro-Wilk test of normality was applied followed by the oneway analysis of variance and the Tukey's post hoc test. The level of significance was set at $5 \%$. The surface color of the elastic ligatures was calculated in accordance with the Commission Internationale de L'Eclairage (CIEL*a*b*) color scale (2004), related to the illuminant standard D65, which divides the color through a mathematical process of colorimetric curve into 3 fields: $L^{*}$ or $\Delta L^{*}$, which represents luminosity or the color values (from black to white), a* or $\Delta a *$ axis, which measures from green to red, and $b^{*}$ or $\Delta b *$, which measures the axis from yellow to blue (Figure 3$)^{16,18,19}$. Thus, an estimation occurs in all three axes of color, aiming for a more complete reading of the color variation of orthodontic elastics.

\section{RESULTS}

Table 1 shows the statistical analysis of the groups and multiple comparisons of them. Table 2 shows a descriptive analysis (mean and standard deviation) of groups according to CIEL*a*b* components before and after the experiment. Figure 4 presents the test specimens after staining, showing the visual difference that each solution

Table 1- Statistical analysis

\begin{tabular}{ccccccccc}
\hline $\begin{array}{c}\text { Statistical } \\
\text { analysis }\end{array}$ & distilled water & Coca-Cola ${ }^{\circledR}$ & tomato sauce & açaí & green tea black tea & coffee & wine \\
\hline$\Delta L(p<0.0001)$ & A & A & A & B & C & D & F & E \\
\hline$\Delta a(p<0.0001)$ & A & A & A & A & A & B & D & C \\
$\Delta b(p<0.0001)$ & A & A & B & B & C & D & D & D \\
\hline$E(p<0.0001)$ & A & A & A & B & C & D & F & E \\
\hline
\end{tabular}

* equal letters represent absence of a statistically significant difference

Table 2- Descriptive analysis (mean and standard deviation) of groups according to CIEL*a*b* components before and after experiment

\begin{tabular}{ccccc}
\hline groups & $\boldsymbol{\Delta} \mathbf{E}^{*}$ mean (s.d.) & $\Delta \mathbf{L}^{*}$ mean (s.d.) & $\Delta \mathbf{a}^{*}$ mean (s.d.) & $\Delta \mathbf{b}^{*}$ mean (s.d.) \\
\hline distilled water & $17.1(0.1841)$ & $17.0(0)$ & $-5.2(1,134)$ & $0.3(0.8179)$ \\
Coca-Cola ${ }^{\circledR}$ & $17.2(0.4372)$ & $17.4(0)$ & $-1.7(2,107)$ & $1.5(1,029)$ \\
tomato sauce & $17.2(0.3464)$ & $17.2(0)$ & $-3.2(1,084)$ & $9.4(0.766)$ \\
açaí & $20(1,359)$ & $19.4(1,525)$ & $-2.7(1,208)$ & $11.9(0.5846)$ \\
green tea & $21.9(0.3169)$ & $28.8(0.3062)$ & $-3.8(1,074)$ & $17.6(0.3653)$ \\
black tea & $26.2(1,554)$ & $26.5(1,297)$ & $3.5(0.6464)$ & $12.7(9,001)$ \\
coffee & $33.7(0.7445)$ & $33.4(0.2271)$ & $6.1(0.4668)$ & $44.8(0.6022)$ \\
wine & $31.4(0.6499)$ & $31.5(1,147)$ & $5.9(4,241)$ & $43.9(2,142)$ \\
\hline
\end{tabular}

s.d.= standard deviation 


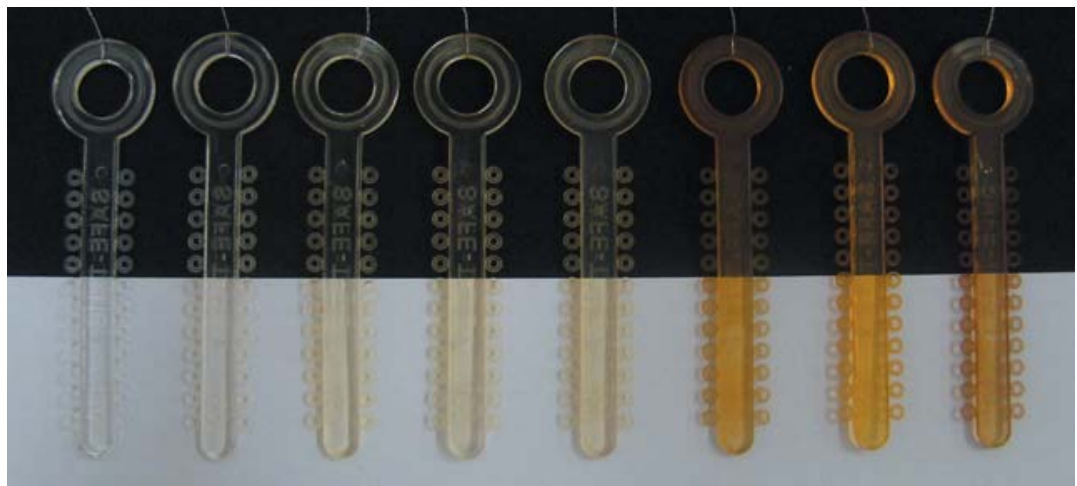

Figure 4- Color alteration after staining - from left to right, distilled water, Coca-Cola ${ }^{\circledR}$, tomato sauce, açaí, green tea, black tea, wine and coffee group

caused on the elastic ligatures.

\section{DISCUSSION}

All the solutions altered the final aspect and color of the test specimens. In an ascending order, staining of the test specimens was as follows: distilled water, Coca-Cola ${ }^{\circledR}$, tomato sauce, açai, green tea, black tea, wine and coffee (Figure 5).

These results become important since adult patients are extremely critical about esthetics of the orthodontic appliance and they are frequent consumers of red wine, coffee and tea. These results are similar to those of Ardeshna and Vaidyanathan ${ }^{2}$ (2009) whose highest colorimetric alterations were found in the tea and coffee groups and the lowest in the group stained by cola, considered clinically acceptable. However, their study did not investigate the color alterations caused by red wine. Red wine, in turn, showed a great staining effect on resin restorations in another study ${ }^{22}$.

These accessories are made by polyurethane synthesis and it involves several stages. Polyurethane is the final product of several chemical reactions that involve various substances. Therefore, polyurethane can be produced with different chemical products. Chemical alteration also influences the configuration of elastomeric chains and their capacity of resisting to deterioration of external agents and processing conditions. Processing conditions may also affect the structure and configuration of the polymer chains. Furthermore, the surface characteristics, such as texture and porosity, may be different and influenced by the external agents ${ }^{2}$.

Studies have shown that exposure of elastomers to water leads to weakening of intermolecular strength and simultaneous formation of hydrogen bridges between the water molecules and elastomer macromolecules. The water molecules facilitate movement of elastomer molecules. This reaction is catalyzed by substances with low $\mathrm{pH}$ such as Coca-Cola ${ }^{\circledR}$, black tea, red wine and coffee. These substances can penetrate into the polymer structure, altering its color ${ }^{10}$. Another important aspect is the concentration of the immersion medium, which could define the greatest staining potential of some substances over other substances; in addition, it is possible that different brands of these coloring agents may present various effects, even due to the coloring degree of each one of them.

Morphological alterations, such as porosity and roughness, may affect color perception because the surface texture modifies the effects of light scattering significantly. Cut elastic modules may present higher porosity due to air trapping during processing. During processing, microfissures may cause light dispersion due to the rough morphology and higher penetration of pigments contributing to greater coloring or discoloring of the sample².

From a clinical perspective, this study showed that transparent elastic ligatures are prone to significant color changes in the oral environment. The dentists must be aware of color instability of elastics to be able to guide patients, who seek for esthetics, with regard to their daily diet. The present study is also important to make the manufacturers aware that the structure of elastics is modified when they are immersed in different solutions.

\section{CONCLUSION}

It may be concluded that among the substances assessed the ones that had a higher staining potential on esthetic elastic ligatures were black tea, coffee and wine, respectively. Knowing this information, the dentist may advise their patients to avoid certain foods because elastic staining may occur thus decreasing the aesthetics of the material.

\section{REFERENCES}

1- Abu-Bakr N, Han L, Okamoto A, Iwaku M. Color stability of compomer after immersion in various media. J Esthet Dent. 2000;12:258-63.

2- Ardeshna AP, Vaidyanathan TK. Colour changes of orthodontic elastomeric module materials exposed in vitro dietary media. J Orthodontics. 2009;36:177-85. 
3- Chan KC, Fuller JL, Hormati AA. The ability of foods to stain two composite resins. J Prost Dent. 1980;43:542-5.

4- Dietschi D, Campanile G, Holz J, Meyer JM. Comparison of the color stability of ten new-generation composites: an in vitro study. Dental Materials. 1994;10:353-62.

5- Eliades T, Gioka C, Heim M, Eliades G, Makou M. Color stability of orthodontic adhesive resins. Angle Orthod. 2004;74:391-3.

6- Faltermeier A, Rosentritt M, Reicheneder C, Behr M. Discoloration of orthodontic adhesives caused by food dyes and ultraviolet light. Eur J Orthod. 2008;30:89-93.

7- Fay RM, Servos T, Powers JM. Color of restorative materials after staining and bleaching. Oper Dent. 1999;24:292-6.

8- Fujita M, Kawakami S, Noda M, Sano H. Color change of newly developed esthetic restorative material immersed in foodsimulating solutions. Dent Mat J. 2006;25:352-9.

9- Geggauf AG, Rosenstiel SF, Langhout KJ, Johnston WM. Evaluating tooth color change from carbamide peroxide gel. J Am Dent Assoc. 1993;124:65-72.

10- Huget EF, Patrick KS, Nunez LJ. Observations on the elastic behavior of synthetic orthodontic elastomer. J Dent Res. 1990;69:496-501.

11- Johnston WM, Kao EC. Assessment of appearance match by visual observation and clinical colorimetry. J Dent Res. $1989 ; 68: 819-22$

12- Kim SH, Lee YK. Measurement of discoloration of orthodontic elastomeric modules with a digital camera. Eur J Orthod. 2009;31:556-62.
13- Lee Y. Colour and translucency of tooth-coloured orthodontic brackets. Eur J Orthod. 2008;30:205-10.

14- Lee YK, Lim BS, Kim CW. Effect of surface conditions on the color of dental resin composites. J Biomed Mater Res. 2002;63:657-63.

15- Leibrock A, Rosentritt M, Lang R, Behr M, Handel G. Colour stability of visible light-curing hybrid composites. Eur J Prosthodont Restor Dent. 1997;5:125-30.

16- McLaren K. The development of the CIE 1976 ( $L^{*} a^{*} b^{*}$ ) uniform colour-space and colour-difference formula. J Soc Dyers Colour. 1976;92:338-41,

17- Razzoog ME, Lang BR, Russel MM, May KB. A comparison of the color stability of conventional and titanium dental porcelain. J Prosthet Dent. 1994;72:453-6.

18- Rosenstiel SF, Gegauff AG, Johnston WM. Duration of tooth color change after bleaching. J Am D Assoc. 1991;122:54-9.

19- Stober T, Gilde H, Lenz P. Color stability of highly filled composite resin materials for facings. Dent Mater. 2001;17:87-94. 20- Um CM, Ruyter IE. Staining of resin-based veneering materials with coffee and tea. Quintessence Int. 1991;22:377-86.

21- Wiltshire W, Labuschagne P. Staining of light-cured aesthetic resin restorative materials by different staining media: an in vitro study. J Dent Assoc S S Afr. 1990;45:561-5.

22- Yannikakis SA, Zissis AJ, Polyzois GL, Caroni C. Color stability of provisional resin restorative materials. J Prosthet Dent. 1998; 80:533-9.

23- Ziuchkovski JP, Fields HW, Johnston WM, Lindsey DT Assessment of perceived orthodontic appliance attractiveness. Am J Orthod Dentofacial Orthop. 2008;133:S68-78. 